\title{
Oncoplastic Breast Surgery: From Oblivion to Mainstream
}

\author{
Melvin J. Silverstein, MD $^{1,2}$ \\ ${ }^{1}$ Hoag Memorial Hospital Presbyterian, Newport Beach, CA; ${ }^{2}$ Keck School of Medicine, University of Southern \\ California, Los Angeles, CA
}

\section{WARNING}

The swell is building

The wave is coming

It will break on your shore

Get a board and get on

Or the wave will sweep you out to sea.

\section{PREQUEL}

In 2009, I saw a 42-year-old divorced woman. A general surgeon had removed the entire upper outer quadrant of her left breast, leaving a dented, deformed remnant of a breast with the nipple rotated laterally and superiorly. The pathology report called it benign fibrosis and fibrocystic change. When she took her gown off so that I could examine her, she looked at me sadly and said, "This has ruined my life."

I asked her surgeon about the case. Completely unaware of the impact that removing $25-30 \%$ of her breast had caused, he said, "Big mass and I removed it." That was his training. And for a lingering few, this story continues to be true today. No one ever taught this surgeon, nor many general surgeons, that the appearance of the breast after "lumpectomy" was important.

By 2009, there was uniform agreement that every suspicious mass should undergo needle biopsy prior to removal. ${ }^{1}$ That was not done in this case. Had it been done, the excision, the deformity, the aftermath, all could have been avoided. Had he been trained in oncoplastic breast surgery, the result would have been far better, or more likely, the procedure would never have been done.

(C) Society of Surgical Oncology 2019

First Received: 18 March 2019;

Published Online: 7 May 2019

M. J. Silverstein, MD

e-mail: melsilver9@gmail.com; Melvin.silverstein@hoag.org

\section{EVOLUTION}

Oncoplastic surgery began in the early to mid-1980s for a handful of forward-thinking European and American surgeons, so it is not a new concept. But it was not widely accepted or practiced. Very few surgeons in the USA knew much about it until the American Society of Breast Surgeons (ASBrS) sponsored its first oncoplastic course during the pre-meeting session in 2004. The course was organized and run by Pat Whitworth and me from 2004 to 2012 and then by others. The topic of oncoplastic surgery was not included in the main program until 2012 when Mike Dixon and I debated "Oncoplastic Surgery: Are We Doing Too Much or Too Little?"

By 2017, there was a desire by most members of the ASBrS for greater knowledge in oncoplastic surgery, and the ASBrS took the important step of forming an Oncoplastic Surgery Committee, charged with performing a needs assessment and developing an educational plan for the next 5-10 years. In 2018, the committee published the results of a survey, indicating that there was great interest among members in learning oncoplastic surgery but only $19 \%$ of members reported performing a reduction excision and only $10 \%$ had performed a contralateral procedure for symmetry. ${ }^{2}$

In 2019, the ASBrS and the Oncoplastic Surgery Committee published, in this issue of the Annals, a consensus statement defining and classifying oncoplastic surgery. ${ }^{3}$ That same year, at the Annual Meeting of the ASBrS, an entire session devoted to oncoplastic surgery was, for the first time, included in the main program, demonstrating the society's commitment to oncoplastic surgery and its desire to bring it into the mainstream of surgical practice.

\section{HISTORY}

I was a surgical resident in Boston from 1965 to 1970. The training was Halstedian. Dr. Bernard Fisher, who was changing the paradigm on how we thought about breast 
cancer, had not yet made a biologic impact on the city, which at that time, considered itself the center of the medical universe. ${ }^{4}$ During my residency, I never saw an operation for breast cancer other than a Halsted radical mastectomy. At that time, most clinicians thought all breast cancer was the same: bad. There was little appreciation of the heterogeneity of the disease. It was not the nuanced spectrum of illnesses that we appreciate today.

After residency, I spent two years in the US Army, much of it at Dewitt Army Hospital, Ft. Belvoir, Virginia. There were many retired military personnel living in the surrounding community, and there was lots of breast cancer. I did what I was trained to do-radical mastectomies. I never did less than a radical mastectomy, not once. It never occurred to me to do less. None of my colleagues did less. I had no appreciation of the deformity, the emotional pain, or the devastation I caused. Based on my training, I believed I was treating breast cancer correctly and curing patients. I thought I was a hero.

Next, I spent 3 years at UCLA, as a surgical oncology fellow, with the amazing Donald L. Morton, MD. I was Dr. Morton's first fellow. My eyes were opened as I learned about the immunology and biology of cancer. During the beginning of that fellowship, we did radical mastectomies for breast cancer. By the end, we were doing pectoralispreserving modified mastectomies. There was no immediate reconstruction at that time. Nevertheless, preservation of the pectorals major muscle was a far less deforming and debilitating procedure and a major step forward. It represented letting go of an idea that had been firmly in place for almost 100 years.

In 1979, I opened the Van Nuys Breast Center, the first free-standing breast center in the USA. ${ }^{5}$ We had doctors from every subspecialty that treated breast cancer, and it was a fertile environment for change. The first major change came in July 1981. The great Italian surgeon, Umberto Veronesi published the Milan I trial, a prospective randomized study comparing Halsted radical mastectomy with quadrant resection, axillary lymph node dissection, and radiation therapy. ${ }^{6}$ News of the publication made the front page of the New York Times.

In his New England Journal article, Veronesi et al. reported no difference in disease-free or overall survival between the two treatment arms, and those data held up 20 years later. ${ }^{7}$ This was the first randomized trial showing that a breast-preserving procedure resulted in an equal survival rate, with far less deformity and morbidity, when compared with radical mastectomy.

Our group in Van Nuys reasoned, if survival was equal, then breast conservation was more equal. We became early adopters of breast conservation, and it played a major role in our success as others around us continued to do mastectomies. Women wanted breast conservation, and they sought it out. By 1985, and with the publication of National Adjuvant Breast and Bowel Project Protocol B- $0^{6,8}$ breast conservation had become our default procedure for patients with stage I and II breast cancer and DCIS $\leq 5 \mathrm{~cm}$.

Initially, I created some surgical deformities as I preserved the breast. Even though I worked with plastic surgeons on a daily basis, it never dawned upon me to integrate plastic surgery as part of a breast-conserving operation. My training was exactly the opposite. I thought it was wrong to open new tissue planes and to move healthy tissue into an area previously occupied by cancer.

As the Van Nuys Breast Center became well known, physicians from all over the world began to visit. In the mid-1980s, Werner Audretsch from Dusseldorf came. He was using a range of volume displacement excisions to remove tumors and reshape the breast. ${ }^{9} \mathrm{He}$ opened planes that were normally not opened, and he moved tissue with no untoward oncologic results. He was doing exactly what I had been taught NOT to do. He initially called it "tumorspecific surgery." A few years later, he would be the first to coin the term "oncoplastic surgery." Krishna Clough from Paris also visited. ${ }^{10} \mathrm{He}$, too, was using reduction excisions to conservatively treat breast cancer with excellent cosmetic and oncologic results.

Both Audretsch and Clough had a profound effect on us. We adopted a philosophy that the appearance of the breast after breast conservation was important, a simple concept that had never been taught to any of us. We began to include our plastic surgeons in preoperative planning. We embraced the reduction excision. Over time, we modified it, developing the split reduction, to meet the needs of the tumor. ${ }^{11}$ We pushed this concept as far as possible, finally developing extreme oncoplasty, which we defined as breast conservation for patients whose tumors exceed the standards for breast conservation, and who in most physicians' opinions, need a mastectomy. ${ }^{12,13}$ Extreme patients are those with tumors larger than $5 \mathrm{~cm}$, multifocal/multicentric lesions, recurrences in previously irradiated breasts, large tumor size relative to breast size, etc.

\section{WIN-WIN}

When I started training as a surgical oncologist, cancer surgery, for most patients, had generally been a lose-lose experience. First: a big operation to remove the tumor accompanied by significant morbidity and deformity. This was often followed by the second loss, which was recurrence and death. What kept us going was that, sometimes, it was a lose-win. There was significant deformity and morbidity but no recurrence and the patient lived to die of something else at a much later time. But now, with 
oncoplastic breast conservation surgery, a win-win is finally possible. We can remove the tumor and repair the defect. The patient looks better than she started, and the tumor never recurs: a true win-win, unheard of for the first 100 years of surgical oncology.

\section{THE ASBRS MAKES A MAJOR COMMITMENT}

In this issue of the Annals, Chatterjee at al., representing the American Society of Breast Surgeons, take a giant step, as they bring oncoplastic breast conservation surgery into the mainstream. ${ }^{3}$ They present us with a consensus definition and classification system for oncoplastic breast surgery.

I have always defined oncoplastic surgery simply, as a breast-conserving operation that combines oncologic principles with plastic surgical techniques. But my definition is vague and not precise about either of its components. The authors fine-tune the definition by calling it "an oncologic partial mastectomy with ipsilateral defect repair, using volume displacement or volume replacement techniques with contralateral symmetry surgery as appropriate." Hard to say in one breath, but well-done on the definition.

The authors have considered many factors in their oncoplastic surgery classification, but for simplicity, they have classified oncoplastic surgery volumetrically, into two levels, based on the percentage of the breast removed: level I, removal of less than $20 \%$, and level II, removal of 20-50\%. That does not quite work for me. When I think about an oncoplastic resection, I think about much more than the volume I plan to resect. I consider the ratio of tumor size to breast size, the position of the tumor in the breast, the degree of ptosis, the density of the breast, and the patient's feelings about her personal anatomy and goals for the final result. While the percentage of tissue removed may well be the most important factor, I do not believe that a two-tiered classification, based on volume alone, can do justice to this complex subject. I would prefer a classification based on the difficulty of the tissue/skin rearrangement, as well as the volume of resection.

Level I should refer to easier cases that just about any surgeon can do, such as local tissue advancement or a crescent resection, etc. It should include deepithelialization, undermining, and nipple repositioning.

Level II should refer to more complicated cases that take special training to be able to perform, such as a reduction or a Benelli resection. A Benelli resection of a 1-cm tumor in the upper inner quadrant, requiring elevation of skin flaps, creation of glandular flaps, recreation of a breast mound, and centralization of the nipple-areolar complex may not meet the volume requirement of $20 \%$, but it is clearly difficult, and therefore, in my opinion, a level II case.
I think there should be a level III and level IV to represent advanced levels of difficulty. Level III should include complicated skin patterns such as split Wise patterns or clamshells, patients with prior mammoplasties, and second chances in patients with prior radiation therapy. Level III cases should also include those that require volume replacement with breast implants or autologous tissue transfer with local intercostal perforator flaps, such as lateral intercostal artery perforator (LICAP) flaps.

Level IV should consist of regional or distant flaps, such as latissimus dorsi, thoracodorsal artery perforator (TDAP), or abdominal based flaps (pedicled or with microvascular anastomoses). It is yet to be seen whether volume replacement with autologous fat injections will be an accepted method of partial breast reconstruction, but it is likely a level III or IV procedure.

\section{FINALLY}

I applaud the ASBrS for their long-time support of oncoplastic surgery as evidenced by their pre-meeting courses and now their commitment to creating an environment in which all current and future breast surgeons have some oncoplastic skills. Going forward, an oncoplastic mindset should be brought to every breast conservation case, even if it is only a simple excision.

Most of us find ourselves somewhere on the journey to oncoplastic excellence, studying, practicing, taking courses, riding the wave rather than allowing it to sweep us out to sea. Our goal should be modern oncoplastic breast conservation with esthetic results equivalent to purely cosmetic procedures.

To achieve that goal, we need to reconsider our training programs. Five years of general surgery followed by a 1-year breast fellowship and a weekend oncoplastic course will not make most of us good oncoplastic surgeons.

In the UK, oncoplastic breast surgery in a recognized surgical subspecialty, with oncoplastic rotations during the last 3 years of surgical training. ${ }^{14}$ The European oncoplastic surgeon does both the oncologic and plastic surgical part of the procedure. One university offers a Master of Surgery Degree in Oncoplastic Surgery. There is also a 1-year oncoplastic fellowship available.

Since we do not have this type of training in the USA, the best approach for most breast surgeons here is to team up with an interested plastic surgeon and do the more difficult cases together for a few years, to learn how to mark the breasts, rotate flaps, move tissues, keep the nipple alive on various pedicles, etc. The most important part of the operation is preplanning the procedure, reviewing the images and the pathology, consulting with all of the involved disciplines, and evaluating all the factors that 
make each breast cancer unique, such as tumor and breast size, tumor position, breast density, ptosis, patient expectations, etc.

The ASBrS, the ASBrS Oncoplastic Committee, and the authors of the consensus statement, three of whom are my prior fellows, are to be commended as they nudge oncoplastic breast conservation into the mainstream of everyday care, establishing the line upon which we all exist. Oncoplastic surgery is now a recognized, emerging, and evolving set of skills. We strive for it someday to become the "standard of care."

ACKNOWLEDGMENT Great thanks are due to my colleagues Sadia Khan D.O. and Nirav Savalia, M.D. and my dear wife Lynna Silverstein. They were all forced to read multiple versions of this editorial. They did so kindly and contributed greatly.

\section{REFERENCES}

1. Silverstein MJ, Recht A, Lagios MD, Bleiweiss I, Blumencranz P, Gizienski T, et al. Image-detected breast cancer: state-of-theart diagnosis and treatment. J Am Coll Surg Consensus Conference III. J Am Coll Surg. 209:504-20.

2. Chatterjee A, Gass J, Burke B, Kopkash K, El-Tamer MB, Holmes D, et al. Results from the American Society of Breast Surgeons Oncoplastic Surgery Committee 2017 survey: current practice and future directions. Ann Surg Oncol. 2018, 25:2790-2794.

3. Chatterjee A, Gass J, Patel K, Holmes D, Kopkash K, Peiris L, et al. A consensus definition and classification system of oncoplastic surgery developed by the American Society of Breast Surgeons. Ann Surg Oncol. 2019, 25 (in press, this issue).

4. Fisher B. The surgical dilemma in the primary therapy of invasive breast cancer: a critical appraisal. Curr Prob Surg. 1970, 10:3-53.
5. Silverstein MJ. The Van Nuys Breast Center-The first freestanding multidisciplinary breast center. Surg Oncol Clin N Am. 2000;9(2):159-75.

6. Veronesi U, Saccozzi R, Del Vecchio M, Banfi A, Clemente C, De Lena $\mathrm{M}$, et al. Comparing radical mastectomy with quadrantectomy, axillary dissection and radiotherapy in patients with small cancers of the breast. N Engl J Med. 1981;305:6-10.

7. Veronesi U, Cascinelli N, Mariani L, Greco M, Saccozzi R, Luni A, et al. Twenty-year follow-up of a randomized study comparing breast-conserving surgery with radical mastectomy for early breast cancer. N Engl J Med. 2002;347:1227-32.

8. Fisher B, Bauer M, Margolese R, Poisson R, Pilch Y, Redmond $\mathrm{C}$, et al. Five-year results of a randomized clinical trial comparing total mastectomy and lumpectomy with or without radiation therapy in the treatment of breast cancer. $N$ Eng $J$ Med. 1985;312:665-73.

9. Audretsch W, Rezai M, Kolotas C, Zamboglou N, Schnabel T, Bojar H. Tumor-specific immediatereconstruction in breast cancer patients. Semin Plast Surg. 1998;11(1):71-100.

10. Clough K, Lewis J, Couturaud B, Fitoussi A, Nos C, Falcou M. Oncoplastic techniques allow extensive resections for breast conserving therapy of breast carcinomas. Ann Surg. 2003;237:26-34.

11. Silverstein MJ, Savalia N, Khan S, et al. Oncoplastic split reduction with intraoperative radiation therapy. Ann Surg Oncol. 2015;22(10):3405-6.

12. Silverstein MJ, Savalia N, Khan S, Ryan J. Extreme oncoplasty: breast conservation for patients who need mastectomy. Breast $J$. 2015;21:52-59.

13. Silverstein MJ. Radical mastectomy to radical conservation (extreme oncoplasty): a revolutionary change. J Am Coll Surg. 2016;222:1-6.

14. Down S, Peieira J, Leinster S, Simpson A. Training the oncoplastic breast surgeon-current and future prospective. Gland Surg. 2013;2:126-7.

Publisher's Note Springer Nature remains neutral with regard to jurisdictional claims in published maps and institutional affiliations. 